\title{
Acute inflammation in young children inhibits C-type natriuretic peptide
}

\author{
Timothy C.R. Prickett ${ }^{1}$, James Hector-Taylor ${ }^{2}$, Robert C. Olney ${ }^{3}$, Brian A. Darlow² and Eric A. Espiner ${ }^{1}$
}

BACKGROUND: C-type natriuretic peptide (CNP) is a paracrine growth factor critical in endochondral bone growth. Amino-terminal CNP (NTproCNP), measurable in plasma, correlates with growth-plate activity and can be used as a biomarker of growth velocity in children. Because severe inflammation in adults increases CNP, we studied CNP peptides and inflammatory markers in children with acute illness.

METHODS: Forty-two children aged 2 mo to 5 y with acute illness warranting admission to an acute assessment unit were studied. Fifteen age-matched healthy children attending an outpatient clinic served as controls. Venous CNP concentrations were measured at admission, along with markers of acute inflammation (body temperature, C-reactive protein (CRP), and white blood cell count) in children with acute illness.

RESULTS: NTproCNP and CNP SD scores (SDSs) in the acutely ill group were significantly suppressed $(P<0.001)$ as compared with those of healthy children or healthy population norms. NTproCNP SDS was significantly inversely related to body temperature $(r=-0.42, P<0.01)$ and $\operatorname{CRP}(r=-0.56, P<0.001)$.

CONCLUSION: Acute inflammation in young children potently reduces CNP production, which needs to be considered when screening for growth disorders. Our data raise the possibility that the adverse effects of inflammatory cytokines on skeletal growth may be mediated in part by reduced CNP.

-type natriuretic peptide (CNP) is expressed in a wide range of tissues (1), but its regulation in vivo has been difficult to study because only small amounts of the active peptide enter the circulation. However, recognition that an inactive amino-terminal fragment of proCNP (NTproCNP) is co-secreted with CNP $(2,3)$, is readily measured in plasma, and correlates with tissue CNP production (4), has opened the door to clinical studies - for example, study of changing CNP production during growth and development.

In keeping with evidence showing that an intact CNP signaling pathway is crucial to postnatal endochondral growth $(5,6)$, there is now strong support for the view that plasma concentrations of NTproCNP reflect concurrent linear growth velocity during childhood $(3,7,8)$. Recent studies indicate that plasma NTproCNP concentration accounts for at least 50\% of the variation in growth velocity in healthy children aged
2 mo to 20 y (9). Furthermore, changes in growth velocity initiated by hormone therapy (10) or glucocorticoid drugs (11) are closely correlated with concordant changes in plasma NTproCNP. Together, these findings suggest that, provided other pathophysiological variables are controlled, this peptide may be a useful marker of concurrent growth velocity. During the course of determining a provisional reference range for plasma CNP forms, we observed unusually low concentrations in very young children with intercurrent infections. This finding - unexpected in light of reports in adults showing that plasma CNP forms were raised in acute sepsis-raised the possibility that the CNP response to acute inflammation may differ in growing children. Moreover, because intercurrent infections are common in preschoolers, clarifying any possible impact on CNP regulation would be important when interpreting values in children undergoing tests for growth disorders. Hypothesizing that, as compared with values obtained in healthy children, plasma CNP forms are reduced in young children with acute inflammation and raised acute inflammatory markers, we have studied two groups of children aged 2 mo to $5 \mathrm{y}$. Group 1 comprised 15 healthy ambulant children attending an arranged hospital outpatient clinic and was compared with 42 children presenting with acute illness warranting admission to a child critical care unit (Group 2). Plasma NTproCNP and CNP SD scores (SDSs) were determined and compared with our published reference ranges (9). Results were also used to compare differences between the two groups and identify associations of CNP values with the conventional markers of systemic inflammation, body temperature, C-reactive protein (CRP), and leukocytosis.

\section{RESULTS}

Demographic and clinical data for subjects are listed in Table 1. Subjects with acute illness (Group 2) tended to be younger (median age $1.8(0.9-2.9)$ y) than those in Group 1 (median age $2.2(1.6-4.3)$ y, $P=0.15)$. Height SDSs for Group 1 were not different from the general population. However, subjects in Group 2 were taller than the general population $(P<0.001)$ and taller than those in Group $1(P=0.005$, Figure 1$)$.

Despite greater height for age in acutely ill children, their median NTproCNP level (35.5 (27.4-47.9) pmol/l) was lower

'Department of Medicine, University of Otago, Christchurch, New Zealand; ${ }^{2}$ Department of Paediatrics, University of Otago, Christchurch, New Zealand; ${ }^{3}$ Division of Endocrinology, Nemours Children's Clinic, Jacksonville, Florida. Correspondence: Timothy C.R. Prickett (tim.prickett@otago.ac.nz)

Received 28 September 2012; accepted 4 January 2013; advance online publication 3 July 2013. doi:10.1038/pr.2013.92 
than that of Group 1 (46.0 (38.1-62.3) pmol/l). Expressed as NTproCNP SDS, as shown in Figure 2, levels were markedly reduced in Group 2 as compared with values in Group 1 (median: -1.7 and 0.2 , respectively, $P<0.001$ ). Suppression was independent of type of infection. As compared with the general population, Group 1 children had NTproCNP levels that were within the expected range, whereas those in Group 2 had levels that were significantly lower $(P<0.001)$. In the 10 children in Group 2 in whom CNP measurements were possible, CNP SDS (median: -3.7) was profoundly depressed.

Table 1. Subject characteristics

\begin{tabular}{lccc}
\hline & Group 1 & Group 2 & $P^{\mathrm{a}}$ \\
\hline Number & 15 & 42 & \\
Gender $(\mathrm{F}, \mathrm{M})$ & 10,5 & 19,23 & \\
$\begin{array}{l}\text { Age, } \mathrm{y} \text { (median } \\
\text { (interquartile range)) }\end{array}$ & $2.2(1.6-4.3)$ & $1.8(0.9-2.9)$ & 0.15 \\
Duration of hospital stay, d & $\mathrm{N} / \mathrm{A}$ & $3(1-5)$ & \\
\hline
\end{tabular}

F, female; M, male; N/A, not applicable.

astudent's t-test.

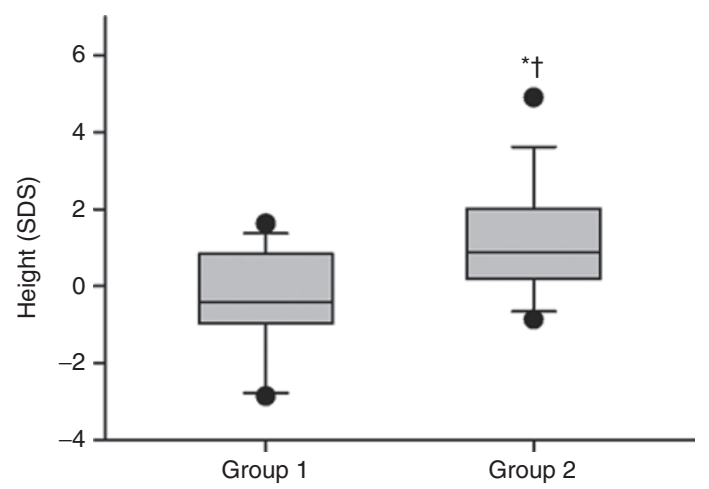

Figure 1. Height SD scores (Height SDSs) for healthy children (Group 1) and acutely ill subjects (Group 2). Box plots show median, 25th and 75th percentiles, 10th and 90th percentiles, and individual outliers. ${ }^{*} P=0.005$ as compared with Group 1. ${ }^{\dagger} P<0.001$ as compared with the general population. NTproCNP, amino-terminal C-type natriuretic peptide; SDS, SD score.

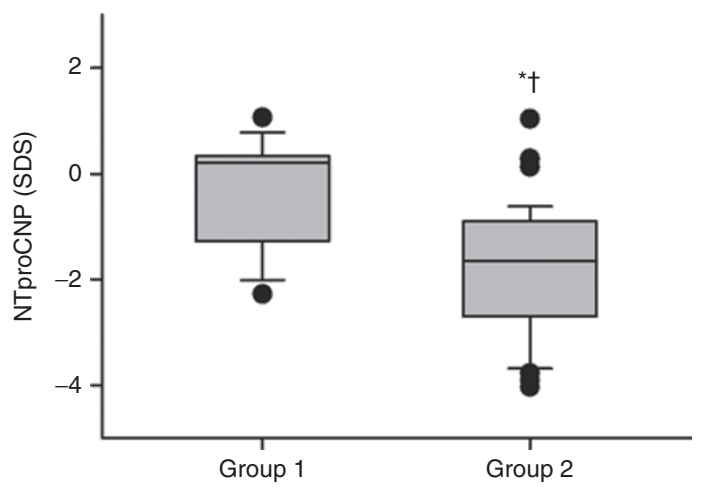

Figure 2. Box plot of NTproCNP SDSs in healthy children (Group 1) and acutely ill subjects (Group 2). Shown are median, 25th and 75th percentiles, 10th and 90th percentiles, and individual outliers. ${ }^{*} P<0.001$ as compared with Group 1. ${ }^{\dagger} P<0.001$ as compared with the general population. NTproCNP, amino-terminal C-type natriuretic peptide; SDS, SD score.
Further analysis of Group 2 children shows that plasma NTproCNP SDS is significantly and inversely related to body temperature (Figure 3a, $r=-0.42, P<0.01$ ) and CRP (Figure 3b, $r=-0.56, P<0.001$ ). No relationship with the total white cell blood count or neutrophil count was observed $(r=$ $-0.07, P=0.7$ and $r=-0.17, P=0.3$, respectively).

\section{DISCUSSION}

The current results show that, as compared with healthy ambulant outpatients and a healthy population of normal children, plasma NTproCNP is significantly depressed during acute illness in infants and young children. Moreover, the degree of suppression is highly correlated with conventional markers of acute inflammation in sick preschool-aged children. Together, these findings indicate that the inflammatory response and/or the associated stress rapidly reduce CNP production in skeletal tissues. These findings not only provide new insights into CNP regulation but also on a more pragmatic note require consideration when interpreting plasma NTproCNP values as a marker of growth velocity.

Clarifying the major sources of circulating concentrations of CNP forms, as well as the effects of pathophysiological variables on plasma levels, is increasingly important now that laboratory assays are being used in humans to quantify CNP production $(7,8,12)$. Values of both NTproCNP and CNP were higher during the growing years (9) and then fell
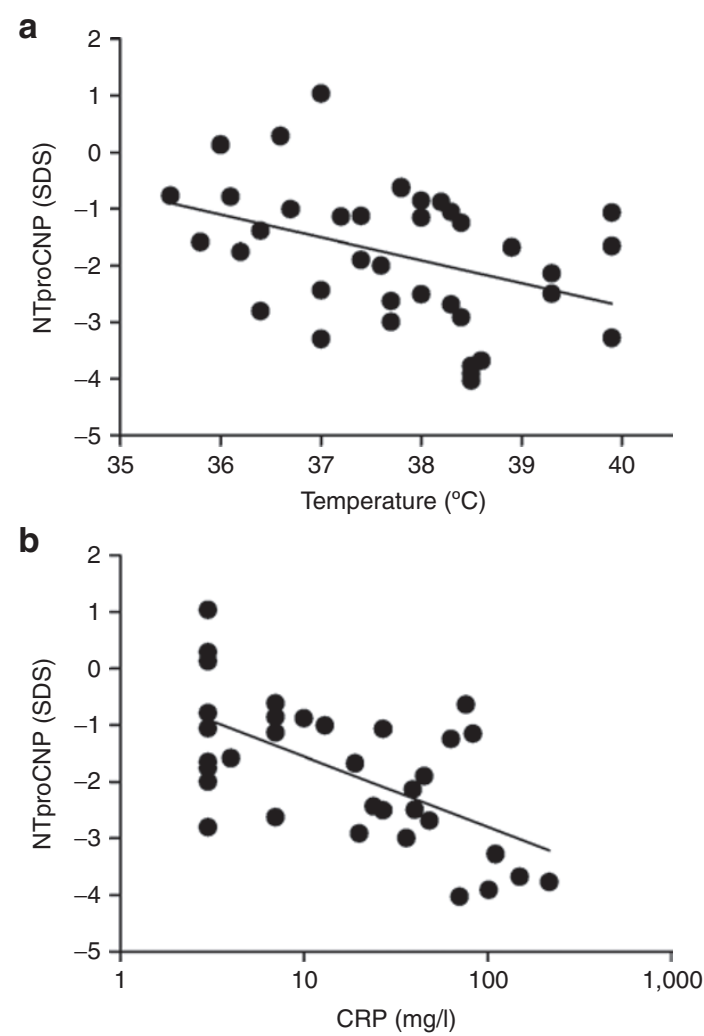

Figure 3. The association between plasma NTproCNP SDS and (a) body temperature $(r:-0.42, P<0.01)$ or (b) CRP $(r:-0.56, P<0.001)$ in acutely ill subjects (Group 2). CRP, C-reactive protein; NTproCNP, amino-terminal C-type natriuretic peptide; SDS, SD score. 
progressively to reach a nadir by the fifth decade in a population of adult-volunteer subjects (13). Consistent with the well-documented expression of CNP in the vascular endothelium, early work emphasized the importance of the peptide in a "vascular natriuretic peptide system" (14), which was stimulated in vitro by cytokines such as transforming growth factor- $\beta$. Notably, adults with severe sepsis and associated shock and multiorgan failure were found to have markedly raised plasma concentrations of CNP (15)-possibly induced by cytokines (such as tumor necrosis factor- $\alpha$ and lipopolysaccharide) and an activated inflammatory state. More recent studies report similar findings using assays of NTproCNP in critically ill adults (16), with values being increased in the presence of sepsis (17). A strong positive association of plasma NTproCNP with inflammatory markers such as CRP was also documented (17). These findings in critically ill adults stand in contrast with the present observations in young children in which acute inflammation, in most instances infectious in origin, suppressed CNP production as shown by greatly reduced plasma concentrations of both CNP forms. Furthermore, the degree of suppression was significantly and inversely related to markers of acute inflammation such as CRP and fever. Whether these differential responses in plasma CNP and NTproCNP to acute inflammation reflect severity or subjects' maturation is unclear. Severe sepsis with shock is likely to stimulate a much more diverse range of cytokines and higher levels of interleukin (IL)-1 $\beta$ and IL- 6 than acute inflammation not associated with shock $(18,19)$, which, by damaging the vascular endothelium, may allow greater access of potential CNP secretagogues (20) to sites of CNP production and subsequent (luminal) release. Furthermore, organ failure and renal impairment will markedly raise NTproCNP by reducing its clearance (13).

That the CNP response in children to lesser degrees of inflammation contrasts with the above may be related to at least two factors. First, because cytokine release is much lower, the integrity of the vascular endothelium is unlikely to be threatened, and release of "vascular CNP" may be minimal. In unpublished studies, we have found that even massive doses of Escherichia coli lipopolysaccharide $(800 \mathrm{ng} / \mathrm{kg}$, intravenous bolus) in healthy adult sheep resulted in only modest increase in plasma CNP or NTproCNP. Second, and perhaps more important, circulating concentrations of CNP peptides in healthy growing children are largely sourced from growth plate-related tissues $(4,9)$, which are absent in adults. Both CNP production and linear growth can be rapidly reduced in lambs or children by factors known to impair growth, such as nutrient deficiency (21) or high doses of glucocorticoids (3). Because small (contrived) increases in plasma cortisol for a period of $10 \mathrm{~d}$ in fetal lambs also lower NTproCNP (22), stress associated increases in cortisol could contribute to the suppressed levels of CNP we observed. However, the close inverse association of CNP values with CRP and fever suggest that inflammatory cytokines are more likely to be involved. Relevant here are in vitro findings showing that IL-1 $\beta$ (23), IL-6 (24), or a combination of cytokines (25) potently inhibit chondrogenesis, including proliferating chondrocytes (25), which are likely sources of CNP within growth plates (5). Our findings linking inflammation with CNP suppression in young children now call for further study of cytokine actions on both CNP gene expression and CNP signaling within growth-plate tissues.

Our study has some limitations. Because inflammatory markers were not assessed in Group 1 children, we cannot exclude the possibility of an inflammatory state in some of these preschoolers whose height, although not abnormal, was significantly less than that of Group 2 children without examining relevant previous medical history. Moreover, putative specific mediators of the suppression (individual cytokines, cortisol, and other candidates) were not measured. Although such data could assist when focusing on underlying mechanisms in future studies, the central and novel observation that CNP production is profoundly inhibited by endogenous factors associated with acute illness in young children remains incontestable.

Apart from identifying novel mechanisms affecting CNP production, the current findings have important implications for the use of CNP measurements as biomarkers of concurrent linear growth. Although the rates of onset and recovery of inflammatory actions on CNP production are unknown, clearly sampling from children with acute inflammation will not provide a true reflection of their skeletal growth rate in health. Simple measures such as recent medical history, body temperature recording, and clinical inspection should be sufficient to detect ill children prior to sampling. How quickly $\mathrm{CNP}$ peptide levels return to normal is unknown. However, the rapid rebound of CNP levels after withdrawal of chemotherapy in children with acute lymphoblastic leukemia (11), and the rapid NTproCNP rise at age $2 \mathrm{wk}$ in neonates (26) after the postnatal acute-phase reaction abates (27), suggest suppression is likely to be short lived.

In conclusion, acute inflammation in young children markedly inhibits CNP production. The close inverse association of plasma NTproCNP with markers of acute inflammation suggests that cytokines act to reduce CNP production in growth plates. In raising the possibility that reduced CNP in skeletal tissues may also contribute to the adverse effects of chronic inflammation, the findings may have therapeutic applications in disorders of bone growth.

\section{METHODS \\ Subjects}

Group 1 comprised 15 healthy children attending a routine (prearranged) appointment at a specialty hospital outpatient clinic. Children referred for possible disorders of linear growth were excluded. Reasons for clinic attendance included allergy (three subjects), alimentary symptoms (four subjects), previous history of bone infection (two subjects), failure to thrive (two subjects), obesity of unknown cause (two subjects), possible hypothyroidism (one subject, ruled out by laboratory testing), and possible lead poisoning (one subject, ruled out by laboratory testing). None of the 15 children in Group 1 showed signs of acute illness or distress at the time of the prearranged venipuncture. At the time of this blood sampling, which was required for clinical reasons, permission was obtained for an additional $5 \mathrm{ml}$ blood sample for measurement of NTproCNP. None of the children was 
receiving growth stimulants or drugs that are known to affect CNP production, such as corticosteroids (11).

During the same time period of subject selection for Group 1, 42 children-without relevant previous medical history-presenting with an acute illness warranting admission to a child critical care unit were studied (Group 2). Clinical diagnoses included acute respiratory infection (12 subjects), gastroenteric infection (five subjects), renal tract infection (six subjects), possible meningitis (three subjects), soft-tissue infection (three subjects), and other symptoms suspicious of acute infection such as rash, adenitis, or high fever (13 subjects). Duration of symptoms prior to admission was $12 \mathrm{~h}$ to $14 \mathrm{~d}$, with a median of $3 \mathrm{~d}$. Body temperature was recorded at the time of venous sampling for clinically relevant tests plus collection of plasma for NTproCNP, CRP, and white cell blood count after informed consent. When plasma volume was sufficient, CNP was also measured.

In all children, age, height (Harpendon stadiometer or recumbent stadiometer in children $<2 y$ ), and weight were measured at the time of venipuncture, and height SDSs calculated using Centers for Disease Control and Prevention 2000 growth charts (28).

This study was approved by the New Zealand Upper South B Regional Ethics Committee. In all cases, subjects and/or parents/ guardians gave written informed consent.

\section{Assays}

Venous blood was drawn for NTproCNP into EDTA collection tubes (Becton-Dickinson, Plymouth, UK), then placed in ice/water slurry and centrifuged $(2,800 \mathrm{~g}$ for $10 \mathrm{~min})$ within $10 \mathrm{~min}$ of collection. The aspirated plasma was then stored at $-70{ }^{\circ} \mathrm{C}$ until measurement of NTproCNP. When sufficient volume of plasma was available, CNP was also measured in Group 2 infants. NTproCNP was measured by radioimmunoassay as previously described (9). Within- and between-assay coefficients of variation were 6.8 and $8.4 \%$, respectively, at $14 \mathrm{pmol} / \mathrm{l}$. Cross-reactivity with ANP propeptide in this assay was $<0.07 \%$ and with human BNP propeptide was $<0.4 \%$. CNP was also measured by radioimmunoassay as previously described (29) using a commercial CNP-22 antiserum provided by Phoenix Pharmaceuticals (Belmont, CA). Within- and between-assay coefficients of variation were 3.8 and $5.5 \%$, respectively, at $9 \mathrm{pmol} / \mathrm{l}$. The detection limit was $0.5 \mathrm{pmol} / \mathrm{l}$. CNP and NTproCNP SDSs were determined using data from 258 healthy normal subjects aged 2 mo to $20 \mathrm{y}$ as previously described (9). Plasma CRP concentrations were measured on the Abbott c8000 analyzer using the manufacturer's reagents (Abbott Laboratories, Abbott Park, IL).

\section{Statistics}

Results are expressed as median (interquartile range). Comparison of SDS data with those of the general population (mean: 0, SD: 1) were made using one-sample Student's $t$-test. Comparisons between the subject groups were done using a two-tailed Student's $t$-test. Spearman's rank coefficient was used to determine correlations between variables, presented as $r$ values. Statistical significance was assumed when $P<0.05$.

\section{STATEMENT OF FINANCIAL SUPPORT}

J.H.-T. was the recipient of a Freemasons New Zealand Paediatric Fellowship.

Disclosure: The authors have no financial relationships relevant to this article to disclose.

\section{REFERENCES}

1. Minamino N, Aburaya M, Kojima M, Miyamoto K, Kangawa K, Matsuo, $\mathrm{H}$. Distribution of C-type natriuretic peptide and its messenger RNA in rat central nervous system and peripheral tissue. Biochem Biophys Res Commun 1993;197:326-35.

2. Prickett TC, Yandle TG, Nicholls MG, Espiner EA, Richards AM. Identification of amino-terminal pro-C-type natriuretic peptide in human plasma. Biochem Biophys Res Commun 2001;286:513-7.

3. Prickett TC, Lynn AM, Barrell GK, et al. Amino-terminal proCNP: a putative marker of cartilage activity in postnatal growth. Pediatr Res 2005;58:334-40.
4. Prickett TC, Bothwell JC, Yandle TG, Richards AM, Espiner EA. Pharmacodynamic responses of plasma and tissue C-type natriuretic peptide to GH: correlation with linear growth in GH-deficient rats. J Endocrinol 2012;212:217-25.

5. Chusho H, Tamura N, Ogawa Y, et al. Dwarfism and early death in mice lacking C-type natriuretic peptide. Proc Natl Acad Sci USA 2001;98:401621.

6. Olney RC. C-type natriuretic peptide in growth: a new paradigm. Growth Horm IGF Res 2006;16:Suppl A:S6-14.

7. Kilpeläinen L, Ivaska KK, Kuiri-Hänninen T, et al. Urinary osteocalcin and serum pro-C-type natriuretic peptide predict linear catch-up growth in infants. J Bone Miner Res 2012;27:1528-35.

8. Xiao Y, Dong Z, Lu W, et al. Measurement of amino-terminal propeptide of C-type natriuretic peptide in patients with idiopathic short stature or isolated growth hormone deficiency. J Pediatr Endocrinol Metab 2011;24:989-94.

9. Olney RC, Permuy JW, Prickett TC, Han JC, Espiner EA. Amino-terminal propeptide of C-type natriuretic peptide (NTproCNP) predicts height velocity in healthy children. Clin Endocrinol (Oxf) 2012;77:416-22.

10. Olney RC, Prickett TC, Yandle TG, Espiner EA, Han JC, Mauras N. Amino-terminal propeptide of C-type natriuretic peptide and linear growth in children: effects of puberty, testosterone, and growth hormone. J Clin Endocrinol Metab 2007;92:4294-8.

11. Prickett TC, Lyver A, Wilson R, Espiner EA, Sullivan MJ. C-type Natriuretic Peptide: a novel biomarker of steroid induced bone toxicity in children with acute lymphoblastic leukemia (ALL). Peptides 2012;36:54-9.

12. Czech-Kowalska J, Pludowski P, Dobrzanska A, et al. Impact of vitamin D supplementation on markers of bone mineral metabolism in term infants. Bone 2012;51:781-6.

13. Prickett TC, Olney RC, Cameron VA, Ellis MJ, Richards AM, Espiner EA. Impact of age, phenotype and cardio-renal function on plasma C-type and B-type natriuretic peptide forms in an adult population. Clin Endocrinol (Oxf) 2013;78:783-9.

14. Suga S, Nakao K, Itoh $\mathrm{H}$, et al. Endothelial production of C-type natriuretic peptide and its marked augmentation by transforming growth factor-beta. Possible existence of "vascular natriuretic peptide system". J Clin Invest 1992;90:1145-9.

15. Hama N, Itoh H, Shirakami G, et al. Detection of C-type natriuretic peptide in human circulation and marked increase of plasma CNP level in septic shock patients. Biochem Biophys Res Commun 1994;198: 1177-82.

16. Bahrami S, Pelinka L, Khadem A, et al. Circulating NT-proCNP predicts sepsis in multiple-traumatized patients without traumatic brain injury. Crit Care Med 2010;38:161-6.

17. Koch A, Voigt S, Sanson E, et al. Prognostic value of circulating aminoterminal pro-C-type natriuretic peptide in critically ill patients. Crit Care 2011;15:R45.

18. Gabay C, Kushner I. Acute-phase proteins and other systemic responses to inflammation. N Engl J Med 1999;340:448-54.

19. Cuschieri J, Bulger E, Schaeffer V, et al.; Inflammation and the Host Response to Injury Collaborative Research Program. Early elevation in random plasma IL-6 after severe injury is associated with development of organ failure. Shock 2010;34:346-51.

20. Suga SI, Itoh H, Komatsu Y, et al. Regulation of endothelial production of C-type natriuretic peptide by interaction between endothelial cells and macrophages. Endocrinology 1998;139:1920-6.

21. Prickett TC, Barrell GK, Wellby M, Yandle TG, Richards AM, Espiner EA. Response of plasma CNP forms to acute anabolic and catabolic interventions in growing lambs. Am J Physiol Endocrinol Metab 2007;292:E1395400.

22. Prickett TC, McNeill BA, Oliver MH, Harding JE, Espiner EA. Effect of cortisol on C-type natriuretic peptide in ovine pregnancy: differential responses in fetal and placental tissues. Pediatr Res 2010;68:462-5.

23. Simsa-Maziel S, Monsonego-Ornan E. Interleukin- $1 ß$ promotes proliferation and inhibits differentiation of chondrocytes through a mechanism involving down-regulation of FGFR-3 and p21. Endocrinology 2012;153:2296-310. 
24. Nakajima S, Naruto T, Miyamae T, et al. Interleukin-6 inhibits early differentiation of ATDC5 chondrogenic progenitor cells. Cytokine 2009;47: 91-7.

25. Mårtensson K, Chrysis D, Sävendahl L. Interleukin-1beta and TNF-alpha act in synergy to inhibit longitudinal growth in fetal rat metatarsal bones. J Bone Miner Res 2004;19:1805-12.

26. Prickett TC, Dixon B, Frampton C, et al. Plasma amino-terminal pro C-type natriuretic Peptide in the neonate: relation to gestational age and postnatal linear growth. J Clin Endocrinol Metab 2008;93:225-32.
27. Marchini G, Berggren V, Djilali-Merzoug R, Hansson LO. The birth process initiates an acute phase reaction in the fetus-newborn infant. Acta Paediatr 2000;89:1082-6.

28. Kuczmarski RJ, Ogden CL, Guo SS, et al. 2000 CDC Growth Charts for the United States: methods and development. Series 11, Data from the national health survey. Vital Health Stat 2002:1-190.

29. Yandle TG, Fisher S, Charles C, Espiner EA, Richards AM. The ovine hypothalamus and pituitary have markedly different distribution of C-type natriuretic peptide forms. Peptides 1993;14:713-6. 